\title{
Usefulness of Standard BMI Cut-Offs for Quality of Life and Psychological Well-Being in Women
}

\author{
Paulo N. Vieira ${ }^{a}$ António L. Palmeirab Jutta Mata ${ }^{a}$ \\ Ronette L. Kolotkin ${ }^{c} d$ Marlene N. Silva ${ }^{a}$ Luís B. Sardinha ${ }^{a}$ \\ Pedro J. Teixeira ${ }^{a}$ \\ ${ }^{a}$ Interdisciplinary Center for the Study of Human Performance, Faculty of Human Kinetics, \\ Technical University of Lisbon, ${ }^{b}$ Department of Humanities and Technology, Campo Grande, \\ Lusófona University, Lisbon, Portugal, ' Obesity and Quality of Life Consulting, ${ }^{d}$ Department \\ of Community and Family Medicine, Duke University Health System, Box 2914 Medical \\ Center, Durham, NC, USA
}

Key Words

Quality of life $\cdot$ Well-being $\cdot$ BMI $\cdot$ Obesity $\cdot$ Women

\begin{abstract}
Objective: We examined BMI-based obesity categories and risk for poor health-related quality of life (HRQOL) and psychological well-being (PWB). Methods: Participants were 1,795 women aged $35.3 \pm 10.2$ years with a mean BMI of $26.6 \mathrm{~kg} / \mathrm{m}^{2}$, not seeking treatment (55\%) or upon entry into a weight control program. Assessments included general HRQOL, weightrelated HRQOL, self-esteem, and body image. Results: All variables, except general HRQOL, were different $(p<0.001)$ between normal-weight and overweight/obese women. For weightrelated HRQOL and body image, worse psychosocial scores were observed linearly with higher obesity levels. Self-esteem was lower in overweight and obese women in comparison with normal-weight women, with no difference between class I and class II obesity. Participants entering a clinical program reported higher physical HRQOL, but lower self-esteem and poorer body image than community-dwelling women of equal weight. Conclusions: BMI categories are useful for identifying increased impairment in PWB and HRQOL in overweight and obese (class I or II) women. Women with a BMI under $25 \mathrm{~kg} / \mathrm{m}^{2}$ reported improved well-being and $\mathrm{HRQOL}$ in comparison to overweight or obese women. However, this relation may not be linear across all psychosocial outcomes, with unique patterns emerging for the association of obesity level with specific dimensions of PWB and HRQOL. C Copyright $\odot 2012$ S. Karger GmbH, Freiburg
\end{abstract}


Vieira et al.: Usefulness of Standard BMI Cut-Offs for Quality of Life and

Psychological Well-Being in Women

\section{Introduction}

Obesity has a significant impact on physical health, and its negative medical consequences are well-documented. A high BMI has been linked to shorter life expectancy [1] and risk of several comorbidities such as metabolic syndrome, osteoarthritis, sleep apnea, cardiovascular disease, hypertension, diabetes, dyslipidemia, and certain forms of cancer [2-4]. In recent years, the psychological consequences of obesity have received more attention; research suggests that overweight and obesity negatively affect quality of life and well-being [5, 6] as well as subjective health status, particularly in the dimension of physical well-being [7]. For example, data from the Canadian Multicentre Osteoporosis Study showed that excess weight has a substantial negative effect on health-related quality of life (HRQOL), particularly in women [8]. Two review articles concluded that impairments on physical functioning and psychosocial functioning are associated with greater degrees of obesity [9] and that there appears to be a dose-response association between greater BMI and degree of HRQOL impairment, producing decreases in functional status and subjective well-being [10]. Additionally, a meta-analysis of studies on obesity and body image suggests a link between obesity and body image dissatisfaction among the obese population - obesity might affect body image through psychological distress, which has an impact on quality of life [11].

International guidelines classify overweight and obesity based on BMI $\left(\mathrm{kg} / \mathrm{m}^{2}\right)$. BMI categories - normal weight $\left(18.9-24.9 \mathrm{~kg} / \mathrm{m}^{2}\right)$, overweight $\left(25.0-29.9 \mathrm{~kg} / \mathrm{m}^{2}\right)$ as well as obesity class I (30.0-34.9 kg/m²), class II $\left(35.0-39.9 \mathrm{~kg} / \mathrm{m}^{2}\right)$, and class III $\left(40.0 \mathrm{~kg} / \mathrm{m}^{2}\right.$ or higher) [12] - are important for specifying obesity-related physical health risk, for example, the transition from normal weight to overweight is a critical cut-point that predicts an increase in overall cardiovascular disease (CVD) risk factors $[12,13]$; when a person's BMI exceeds $30 \mathrm{~kg} / \mathrm{m}^{2}$ and especially $35 \mathrm{~kg} / \mathrm{m}^{2}$, an increase in mortality from several causes is well documented [14]. Accordingly, the National Institutes of Health (NIH) recommend weight loss therapy for persons with a BMI over $30 \mathrm{~kg} / \mathrm{m}^{2}$, and for persons with a BMI between 25 and $29.9 \mathrm{~kg} / \mathrm{m}^{2}$ or a high-risk waist circumference and two or more risk factors [15]. In Portugal, the prevalence of overweight and obesity is $53.6 \%$ for adults, $14.4 \%$ of whom are obese; in adult women, $13.4 \%$ are obese and $34.4 \%$ are overweight [16]. However, very few of these women have a BMI above $40 \mathrm{~kg} / \mathrm{m}^{2}$. In fact, the majority of obese Portuguese women fit into class I and class II obesity.

Despite their widespread use, it is unclear whether standard BMI cut-offs are meaningful and useful with respect to the social and psychological consequences of overweight and obesity [11]. Several review articles and meta-analyses have found an inconsistent relation between obesity and psychological outcomes, including psychological well-being and quality of life [17-19]. Moreover, mixed evidence has been shown for body image and self-esteem as predictors of weight control [20]. For instance, a large study with US American adults showed that overweight or obese treatment seekers are generally more impaired in obesity-specific quality of life than overweight or obese individuals who do not seek treatment [21]. Fontaine et al. [22] concluded that obese persons who had sought treatment were significantly more impaired in the domains of bodily pain, general health, and vitality HRQOL previous to treatment than those who were not trying to lose weight. Body image problems are highly prevalent in overweight and obese persons [23], especially among those seeking treatment [24], and these persons often engage in treatment with the goal of improving body image, which can result in higher body shape concerns and greater body image dissatisfaction. The previous evidence points out the need to study overweight and obese individuals who are seeking treatment separately from those who are not. 
Vieira et al: Usefulness of Standarc

Psychological Well-Being in Women

Table 1. Sample characteristics

\begin{tabular}{ll}
\hline & $\begin{array}{l}\text { Total sample }(\mathrm{n}=1,795) \\
\text { Mean } \pm \mathrm{SD}\end{array}$ \\
\hline Age, years & $35.3 \pm 10.2$ \\
Weight, kg & $69.5 \pm 14.0$ \\
Height, $\mathrm{m}$ & $1.62 \pm 0.1$ \\
BMI, $\mathrm{kg} / \mathrm{m}^{2}$ & $26.6 \pm 5.3$ \\
\hline & Total sample \\
& $\%$ \\
\hline Overweight & 29.0 \\
Obese & 26.6 \\
\hline
\end{tabular}

The goal of this study was to examine the association of obesity level with quality of life and psychological well-being in a large sample of women, comparing normal-weight, overweight, and obese (classes I and II) participants. More specifically, we sought to investigate whether BMI-defined cut-offs are useful for identifying levels at which quality of life and psychological well-being might be at risk. As a complementary analysis, we studied the potential moderating role of treatment seeking status on the relation between obesity level and psychological well-being. We hypothesized that HRQOL and psychological well-being would be decreased in women with higher BMI and in those seeking treatment. To our knowledge, this is the first study examining both HRQOL and psychological well-being variables in overweight/ obese individuals entering obesity treatment and in the community at large.

\section{Material and Methods}

\section{Sample}

Participants were 1,795 adult women with a BMI between 18 and $40 \mathrm{~kg} / \mathrm{m}^{2}$, recruited from the community (54.8\%) or upon entry into two weight control programs (45.2\%). Sample characteristics used in the main analysis of this work are described in table 1. For the purpose of the complementary analysis, we considered two sub-samples: 'non-clinical' and 'clinical'. Women in the community ('non-clinical') subsample ( $\mathrm{n}=984$ ) had to be over 18 years old, not enrolled in a formal weight loss treatment program, and stated that they were not presently attempting to lose weight. The majority of these women met the criteria for being premenopausal and not being pregnant ( $\mathrm{n}=585$ out of 984 ). For the remaining women in the sample, information on menopause is not available but it can be assumed that most of them are premenopausal as 380 out of 399 participants were younger than 50 years old. They were recruited in multiple contexts such as schools, worksites, and health/medical centers through flyers, newsletters, listserv/emailing, and word of mouth. Among the treatment seeking ('clinical') group, 811 women entered one of two behavioral weight loss programs targeting changes in physical activity and dietary habits [25, 26], or volunteered to participate in a 4-month obesity prevention community-based program targeting changes in physical activity and diet [27]. Approval was obtained from the Faculty of Human Kinetics' Ethics Committee, and all participants signed an informed consent form.

\section{Instruments}

Psychosocial Variables

For women in the clinical group, data were collected at baseline in each weight loss program during one laboratory session. For women in the non-clinical group, questionnaires were generally completed at the location of recruitment, individually or in small groups, in some cases without direct supervision. 
Vieira et al: Usefulness of Standard BMI Cut-Offs for Quality of Life

Psychological Well-Being in Women

Instruments were validated Portuguese versions of some of the most commonly used psychosocial instruments in obesity research and are described in detail below. Due to different assessment protocols in each sub-study, not all participants filled out all assessment instruments. The following numbers of participants were available for each of the instruments: general HRQOL $N=1,270$; weight-related measure of HRQOL $N=1,310$; self-esteem $N=1,374$; body image dissatisfaction $N=1,639$; body shape concerns $\mathrm{N}=975$.

\section{Health-Related Quality of Life}

To measure general HRQOL, 985 participants completed the SF-36 questionnaire [28] composed of two scales and a total of 36 items, reflecting physical (physical component summary (PCS)) and psychological (mental component summary (MCS)) composite values (Cronbach's $\alpha$ for the PCS and MCS were 0.76 and 0.85 , respectively). An additional 285 women completed the SF-12 questionnaire (Cronbach's $\alpha$ for the PCS and MCS were 0.65 and 0.78 ), which consists of a subset of 12 items that make up the original SF-36 [29]. When cross-validated in the Medical Outcomes Study, the physical and mental components of the 12-item version explained a major portion of the variance in the SF-36 composite scores $\left(\mathrm{R}^{2}=0.905\right.$ for PCS and 0.938 for MCS) [30]. It has been shown that the SF-12 correlates highly with SF-36 in obese and non-obese patients [31].Furthermore, in our sub-sample measured with SF-36, we calculated an SF-12 score. Thus all HRQOL analyses are expressed using SF-12 scores, with higher scores indicating better HRQOL. Weight-related quality of life was also assessed using the Impact of Weight on Quality of Life-Lite (IWQOL-Lite) [32, 33], a 31-item questionnaire consisting of five subscales: physical function (e.g. 'Because of my weight, I have difficulty getting up from stairs'), self-esteem (e.g. 'Because of my weight, I don't like myself'), sexual life (e.g. 'Because of my weight, I have little or no sexual desire'), public distress (e.g. 'Because of my weight, I worry about finding chairs that are strong enough to hold my weight'), and work (e.g. 'Because of my weight, I have trouble getting things accomplished or meeting my responsibilities'). Cronbach's $\alpha$ was between 0.77 and 0.92 . They can be summarized into a total score (Cronbach's $\alpha$ was 0.93 ), which was used in this study. Items are answered using a 5-point Likert scale from 'never true' to 'always true' and higher scores indicate better weight-related quality of life.

\section{Psychological Well-Being}

Self-esteem was assessed with the Rosenberg Self-Concept/Self-Esteem Scale [34], composed of ten items such as 'I feel I do not have much to be proud of' or 'I feel that I have a number of good qualities', evaluated on a 4-point Likert scale from 'strongly agree' to 'strongly disagree' (Cronbach's $\alpha=0.86$ ). Higher scores represent greater self-esteem. Body image dissatisfaction was measured with the Body Image Assessment Questionnaire [35], which consists of nine silhouettes of increasing size. Participants are asked to choose their current (i.e., perceived actual body size) and ideal figures. The difference between the actual and ideal body size is an indicator of body image dissatisfaction (Cronbach's $\alpha=0.80$ ) and addresses the evaluative dimension of body image. Higher scores represent higher body image dissatisfaction. The Body Shape Questionnaire [36], a 34-item instrument, was applied to measure several dimensions of body image, especially the experience of, and preoccupation with, 'being fat' (Cronbach's $\alpha$ was 0.97 ), addressing the investment dimension of body image (i.e., the cognitive-behavioral importance of one's appearance) [37]. Higher values indicate greater body shape concerns and poorer body image.

\section{Body Habitus}

For women in the clinical group, body weight at baseline was measured twice with a standardized procedure [38], with subjects wearing light clothes and no shoes (average was used), using an electronic scale (SECA model 770, Hamburg, Germany). Height was measured twice, and the average of the two values was used for analyses. For women in the non-clinical group, weight and height were self-reported. BMI was calculated for all women. To overcome one possible study limitation, we considered an empirically driven adjustment for self-reported weight and height, based on an epidemiological study with a Portuguese sample [39]. In that study, the percentage of women who had a different obesity category by self-report versus actual BMI measurement was very small: $1.1 \%$ change from 'normal weight' to 'overweight', $0.9 \%$ change from 'normal weight' to 'class I obesity', and $0.3 \%$ change from 'normal weight' to 'class II obesity'. Thus, we used self-reported measures without adjustments. 
Vieira et al: Usefulness of Standard BMI Cut-O

Psychological Well-Being in Women

Table 2. Health-related quality of life and psychological well-being by obesity status

\begin{tabular}{|c|c|c|c|c|c|c|c|c|c|c|}
\hline & \multirow{4}{*}{$\begin{array}{l}\text { Normal } \\
\text { weight }(\mathrm{NW}) \\
(\mathrm{n}=798) \\
\text { mean } \pm \mathrm{SD}\end{array}$} & \multirow{4}{*}{$\begin{array}{l}\text { Overweight } \\
(\mathrm{Ov}) \\
(\mathrm{n}=520) \\
\text { mean } \pm \mathrm{SD}\end{array}$} & \multirow{4}{*}{$\begin{array}{l}\text { Class I } \\
\text { obesity } \\
(\text { Ob.I) } \\
(n=339) \\
\text { mean } \pm S D\end{array}$} & \multirow{4}{*}{$\begin{array}{l}\text { Class II } \\
\text { obesity (Ob.II) } \\
(\mathrm{n}=138) \\
\text { mean } \pm \mathrm{SD}\end{array}$} & \multicolumn{6}{|c|}{ Orthogonal contrasts ${ }^{\mathrm{a}}$} \\
\hline & & & & & \multicolumn{2}{|c|}{$\mathrm{NW} \times(\mathrm{Ov}, \mathrm{Ob})$} & \multicolumn{2}{|c|}{$(\mathrm{NW}, \mathrm{Ov}) \times \mathrm{Ob}$} & \multicolumn{2}{|c|}{ Ob.I $\times$ Ob.II } \\
\hline & & & & & \multicolumn{2}{|l|}{$\mathrm{C} 1^{\mathrm{b}}$} & \multicolumn{2}{|l|}{$\mathrm{C} 2^{\mathrm{c}}$} & \multicolumn{2}{|l|}{$C^{3} d$} \\
\hline & & & & & ES & $\mathrm{p}$ & ES & $\mathrm{p}$ & ES & $\mathrm{p}$ \\
\hline Age, years & $30.5 \pm 8.7$ & $38.6 \pm 9.7$ & $40.3 \pm 9.9$ & $39.5 \pm 9.2$ & & & & & & \\
\hline $\mathrm{BMI}, \mathrm{kg} / \mathrm{m}^{2}$ & $21.8 \pm 1.8$ & $27.4 \pm 1.4$ & $32.2 \pm 1.4$ & $37.3 \pm 1.7$ & & & & & & \\
\hline $\begin{array}{l}\text { HRQOL physical } \\
\text { health }\end{array}$ & $51.3 \pm 6.8$ & $50.0 \pm 6.0$ & $48.4 \pm 7.0$ & $47.5 \pm 7.5$ & 0.33 & 0.628 & 0.38 & 0.001 & 0.12 & 0.228 \\
\hline $\begin{array}{l}\text { HRQOL mental } \\
\text { health }\end{array}$ & $45.9 \pm 10.2$ & $46.9 \pm 9.7$ & $46.9 \pm 9.9$ & $46.4 \pm 9.4$ & 0.09 & 0.502 & 0.06 & 0.610 & 0.05 & 0.708 \\
\hline $\begin{array}{l}\text { Weight-related } \\
\text { HRQOL }\end{array}$ & $93.0 \pm 8.2$ & $82.4 \pm 13.1$ & $73.3 \pm 14.8$ & $63.5 \pm 18.6$ & 1.37 & $<0.001$ & 1.20 & $<0.001$ & 0.59 & $<0.001$ \\
\hline Self-esteem & $34.1 \pm 4.2$ & $30.9 \pm 5.9$ & $30.1 \pm 6.4$ & $31.0 \pm 6.6$ & 0.67 & $<0.001$ & 0.47 & 0.406 & 0.14 & 0.154 \\
\hline $\begin{array}{l}\text { Body image } \\
\text { dissatisfaction }\end{array}$ & $0.6 \pm 0.8$ & $1.9 \pm 0.8$ & $2.4 \pm 0.8$ & $3.0 \pm 1.0$ & 1.88 & $<0.001$ & 1.47 & $<0.001$ & 0.67 & $<0.001$ \\
\hline $\begin{array}{l}\text { Body shape } \\
\text { concerns }\end{array}$ & $63.2 \pm 26.1$ & $86.2 \pm 30.1$ & $94.0 \pm 29.1$ & $101.7 \pm 29.3$ & 0.99 & $<0.001$ & 0.76 & $<0.001$ & 0.26 & 0.069 \\
\hline $\begin{array}{l}\text { HRQOL = Hea } \\
{ }^{\mathrm{a}} \text { Orthogonal } \\
{ }^{\mathrm{b}} \mathrm{C} 1=\text { Compar } \\
{ }^{\mathrm{c}} \mathrm{C} 2=\text { Compar } \\
{ }^{\mathrm{d}} \mathrm{C} 3=\text { Compar }\end{array}$ & $\begin{array}{l}\text {-related qua } \\
\text { trasts using } \\
\text { n between } \\
\text { n between } \\
\text { n between }\end{array}$ & $\begin{array}{l}\text { lity of life } \\
\text { linear regre } \\
\text { ormal weigh } \\
\text { on-obese an }\end{array}$ & $\begin{array}{l}\text { ion adjusting } \\
\text { and overweig } \\
\text { obese, report } \\
\text { ind class II ob }\end{array}$ & $\begin{array}{l}\text { for age and tr } \\
\text { ght or obese, re } \\
\text { ced values are }\end{array}$ & rtec & $\begin{array}{l}\text { group. } \\
\text { values al }\end{array}$ & o val & & & \\
\hline
\end{tabular}

\section{Statistical Analyses}

Statistical analyses were completed using the Statistical Package for the Social Sciences, version 19 (SPSS Inc., Chicago, IL, USA). Linear regression was performed using BMI category as independent variable and quality of life and psychological well-being as dependent variables, adjusting for age. Group differences were determined with orthogonal contrasts, where C1 represents the comparison between normal weight $\left(\mathrm{BMI}<25 \mathrm{~kg} / \mathrm{m}^{2}\right)$ and overweight or obese, C2 represents the comparison between non-obese $\left(\mathrm{BMI}<30 \mathrm{~kg} / \mathrm{m}^{2}\right)$ and obese, $\mathrm{C} 3$ represents the comparison between class I obesity and class II obesity. Mean differences in quality of life and psychological well-being between clinical and non-clinical groups were tested using independent t-tests, within BMI levels. Analysis of covariance (ANCOVA) was used to study the effects of treatment group, obesity level, and their interaction (treatment seeking status $\times$ BMI category) on quality of life and psychological well-being outcomes using age as a covariate. For the effects of treatment, we further adjusted for actual BMI considering that there were significant differences in BMI between the clinical and non-clinical groups. Type 1 error was set at $\alpha=0.05$ (two-tailed) for all tests.

\section{Results}

Quality of life and psychological well-being among the four BMI groups (normal weight, overweight, class I obesity and class II obesity) as well as significance testing for the orthogonal contrasts between the groups or effect sizes are shown in table 2 . The sample sizes shown in table 1, table 2 , and table 3 refer to the number of participants whose BMI scores were assessed. Results showed that physical HRQOL and weight-related measure of 
Vieira et al.: Usefulness of Standard BMI Cut-Offs for Quality of Life and

Psychological Well-Being in Women

Table 3. Treatment seeking and obesity impact on health-related quality of life and psychological well-being

\begin{tabular}{|c|c|c|c|c|c|c|}
\hline & \multicolumn{2}{|l|}{ Overweight } & \multicolumn{2}{|l|}{ Obesity } & \multirow{2}{*}{$\begin{array}{l}\text { Treat. } \\
\text { group }\end{array}$} & \multirow{2}{*}{$\begin{array}{l}\text { Treat. group } \\
\times \text { Ob.Categ. }\end{array}$} \\
\hline & $\begin{array}{l}\text { clinical } \\
(\mathrm{n}=317) \\
\text { mean } \pm \mathrm{SD}\end{array}$ & $\begin{array}{l}\text { non-clinical } \\
(\mathrm{n}=203) \\
\text { mean } \pm S D\end{array}$ & $\begin{array}{l}\text { clinical } \\
(n=403) \\
\text { mean } \pm S D\end{array}$ & $\begin{array}{l}\text { non-clinical } \\
(\mathrm{n}=74) \\
\text { mean } \pm \mathrm{SD}\end{array}$ & & \\
\hline Age, years & $39.6 \pm 8.6$ & $37.3 \pm 10.7^{*}$ & $39.8 \pm 9.1$ & $41.3 \pm 12.1$ & $(0.034)$ & $(<0.001)$ \\
\hline $\mathrm{BMI}, \mathrm{kg} / \mathrm{m}^{2}$ & $27.6 \pm 1.3$ & $27.1 \pm 1.3^{* * *}$ & $33.8 \pm 2.8$ & $32.6 \pm 2.2^{* * *}$ & $(<0.001)$ & $<0.001$ \\
\hline HRQOL physical health & $51.5 \pm 5.6$ & $48.7 \pm 6.1^{* * *}$ & $49.1 \pm 6.8$ & $45.0 \pm 7.5^{* * *}$ & $<0.001$ & 0.096 \\
\hline HRQOL mental health & $46.0 \pm 10.1$ & $47.7 \pm 9.3$ & $46.9 \pm 9.5$ & $46.2 \pm 10.7$ & 0.215 & 0.035 \\
\hline Weight-related HRQOL & $80.2 \pm 13.5$ & $86.3 \pm 11.3^{* * *}$ & $69.9 \pm 16.0$ & $73.7 \pm 19.7$ & 0.496 & 0.021 \\
\hline Self-esteem & $28.3 \pm 6.5$ & $32.8 \pm 4.6^{* * *}$ & $29.5 \pm 6.7$ & $32.9 \pm 4.8^{* * *}$ & $<0.001$ & 0.073 \\
\hline Body image dissatisfaction & $2.1 \pm 0.8$ & $1.6 \pm 0.8^{* * *}$ & $2.6 \pm 0.9$ & $2.3 \pm 1.1^{* *}$ & 0.036 & 0.004 \\
\hline Body shape concerns & $97.8 \pm 26.4$ & $74.6 \pm 29.2^{* * *}$ & $99.6 \pm 27.7$ & $83.7 \pm 31.6^{* * * *}$ & $<0.001$ & 0.051 \\
\hline
\end{tabular}

HRQOL= Health-related quality of life; Treat. = treatment; Ob.Categ. = obesity category.

${ }^{*} \mathrm{p}<0.05,{ }^{* *} \mathrm{p}<0.01,{ }^{* * *} \mathrm{p}<0.001$ for independent $\mathrm{t}$-test comparing clinical and non-clinical groups within obesity levels.

${ }^{a} p$ Values for analysis of covariance (ANCOVA) testing treatment group influence with age and BMI as covariate (note: comparison for age and BMI, indicating in parenthesis, are not adjusted).

${ }^{b} \mathrm{p}$ Values for analysis of covariance (ANCOVA) testing (treatment group $\times$ obesity category) interaction with age as covariate (note: comparison for age, indicating in parenthesis, is not adjusted).

HRQOL differ among the four BMI categories (normal weight, overweight, obesity classes I and II). Generally, participants in higher BMI categories had lower HRQOL than participants in lower categories. However, there were no differences among BMI categories for mental HRQOL. Concerning self-esteem, individuals with normal weight had a higher score than participants classified as overweight or obese. For body image dissatisfaction and body shape concerns, we again found that individuals classified as normal weight had the lowest dissatisfaction and concern scores. Overweight participants showed lower dissatisfaction and body shape concern than obese participants, with the p value between class I and class II obesity for body shape concerns falling just short of statistical significance $(p=0.069)$.

Figure 1 provides a graphical summary of the direction of changes for each independent variable, separated for BMI category.

Next we tested the role of seeking treatment in HRQOL and psychological well-being. We did not include participants with normal weight in these comparisons, as they are less likely to seek weight loss treatment. Also, we did not differentiate class I and class II obesity due to the limited number of non-clinical participants in these two categories. For this analysis, the sample was split into two groups: women who were about to enter a weight control program (clinical group) and women not seeking treatment and not trying to lose weight (non-clinical group). Table 3 shows the comparison between the clinical and non-clinical group, separately for overweight and obesity classifications.

Participants seeking treatment reported significantly higher physical HRQOL, lower self-esteem, and higher body image dissatisfaction and body shape concerns, compared to women in the non-clinical group $(p<0.001)$. Despite no main effects of treatment seeking status, there was a significant interaction between treatment status and obesity category for mental health and weight-related measure of HRQOL. For mental health, overweight nonclinical women were the most protected; the same was true for the IWQOL-Lite measure (higher scores for the overweight community group), whereas being obese and seeking 
Vieira et al: Usefulness of Standard BMICu

Psychological Well-Being in Women

\begin{tabular}{|c|c|c|c|c|}
\hline & \multicolumn{4}{|l|}{ BMI cut-offs } \\
\hline & normal weight & overweight & class I obesity & class II obesity \\
\hline HRQOL physical health & $\leftrightarrow$ & & & \\
\hline HRQOL mental health & $\leftrightarrow$ & & & \\
\hline Weight-related HRQOL & $\searrow$ & & & \\
\hline Self-esteem & $\searrow$ & & & \\
\hline Body image dissatisfaction & $\searrow$ & & & \\
\hline Body shape concerns & $\searrow$ & & & \\
\hline
\end{tabular}

Fig. 1. Arrow represents, for each variable, the direction of change in comparison with the immediately lower BMI category: \= statistically significant worsening of HRQOL; $\leftrightarrow=$ no difference.

treatment was predictive of markedly poorer quality of life. Interactive effects were also noted for body image measures, generally showing worse psychosocial profiles for the clinical obese group. Overall, the analysis of the interaction between treatment seeking status and obesity category shows that the difference in psychological function between clinical and non-clinical was more pronounced in the overweight group.

\section{Discussion}

The primary goal of this study was to examine the relation of obesity level with quality of life and psychological well-being and investigate whether BMI-defined cut-off categories are useful for identifying levels at which psychological well-being is at risk. To briefly summarize our findings, all psychosocial variables, except general HRQOL, were different between normal-weight and overweight or obese individuals. Physical HRQOL was lower in obese than in non-obese women. Furthermore, the higher the BMI category, the lower the weight-related HRQOL scores and the higher body image dissatisfaction. Self-esteem was lower in overweight and obese women than in normal-weight women, and body shape concerns were also lower in overweight and class I obesity women in comparison with normal-weight women (no difference between class I and class II obesity; fig. 1). Overweight and obese individuals seeking treatment reported higher physical HRQOL, lower selfesteem, and poorer body image in comparison to community-dwelling women of similar average body weight. For the overweight group, there were greater differences between clinical and non-clinical women.

The results of this study are generally in line with previous findings regarding HRQOL associations with BMI; for example, the Nurses Health Study in which physical functioning, vitality, bodily pain, and role limitations were inversely related to self-reported BMI in 56,510 participants [40], the Monitoring Cardiovascular Health (MORGEN) study in which physical functioning and bodily pain were associated with higher BMI in 4,041 Dutch individuals [41], and a large study of 109,076 individuals in which physical functioning was more strongly related to self-reported BMI than mental functioning [42]. Two other studies concluded that changes in body weight were associated more strongly with changes in physical health (as measured by PCS) than with changes in mental health (as measured by 
MCS) $[43,44]$. Additionally, Jia et al. [45] found the same pattern of association between scores from the SF-12 and BMI, with larger decrements in the PCS-12 in class II obesity compared to the decreases in MCS-12. As in our study, mental HRQOL was not associated with BMI in the MORGEN study [46]. A novel aspect of the present findings is the analysis of BMI categories across different dimensions of HRQOL and well-being. The differences reported between women with and without obesity could reflect worse physical functioning, which in turn might lead to impaired perceived HRQOL. Obese women reported more physical limitations in their daily tasks, such as walking to the supermarket and climbing stairs, and also more bodily pain, which likely impairs their functioning in daily life [40]. Beyond these individual factors, there are also environmental factors that can contribute to explain the differences in HRQOL and psychological well-being across BMI categories. Overweight and obese people are under constant social pressure to conform to society's standards regarding weight and appearance [47]. At the same time, it is clear that bias, prejudice, and discrimination are part of everyday life for many overweight individuals; these again are associated with negative social and psychological consequences which affect health and well-being [48].

It should be pointed out, however, that there is substantial individual variability in psychosocial functioning among members of the same (high) BMI category. A number of studies conducted by Fitzgibbon and colleagues [49] suggest that obese individuals are not a homogeneous group and thus may not uniformly respond to standardized treatment programs. In fact, treatment seeking status may influence or be a reflection of higher psychological suffering among the overweight/obese. Kolotkin and colleagues [21] showed that obesity-specific HRQOL varied by treatment seeking status and across treatment modalities in a large study $(n=3,353)$ of overweight and obese adults with $67 \%$ women; the more intense the treatment modality (from non-treatment seeking individuals, over clinical trial participants, outpatient weight loss participants, day treatment participants, to gastric bypass patients) the lower the weight-related measure of HRQOL. Although in our sample treatment group did not significantly predict weight-related HRQOL, mean scores were higher in the obese non-clinical group. The small size for this particular group and corresponding large standard deviation may have reduced statistical power for this comparison. In another study using general measures of HRQOL (SF-36), obese persons seeking treatment reported greater bodily pain as well as lower general health, vitality, physical functioning, role-physical functioning [22], which is partially consistent with the findings of the present study. Trying to lose weight proved to be a particularly important factor in overweight persons, with a greater impact on HRQOL and psychological wellbeing compared to obese individuals. For the overweight group, as expected, weight appears to have less impact on HRQOL than for the heavier group. However, our results show that differences in HRQOL and psychological well-being were more pronounced, according to attempting to lose weight status among overweight women. The higher physical HRQOL scores reported in the clinical group, compared to the non-clinical group, were unexpected and run contrary to the worse psychosocial functioning impairment displayed by the treatment seekers. It is possible that persons entering treatment perceive themselves in better physical condition, which then leads them seek programs where physical activity and exercise might be included. Regardless, this finding is not common and needs to be confirmed in future studies.

Strengths of this study include the large sample size and the use of general and specific quality of life instruments, which is a methodological recommendation from previous obesity HRQOL research [50]. Generic measures are applicable to any population and scores may be compared to general population norms as well as across diseases, while diseasespecific measures contain items of particular relevance to patients with the disease and 
have the potential to be more sensitive to smaller differences between groups and smaller changes over time than generic measures, because of their specificity [51]. These factors can potentially explain the differences between BMI categories in specific, but not generic HRQOL measures. To our knowledge, this is the first study to simultaneously measure general and specific HRQOL together with different aspects of psychological well-being in this population.

One limitation of this study is the reduced generalization of results because the sample was exclusively composed of women. Due to the varying data collecting procedures across participants in this study, we do not have complete socioeconomic data for all our participants, which preclude us from analyzing the impact of socioeconomic status on BMI and HRQOL. Therefore, we cannot entirely exclude the possibility that outcomes were influenced by socioeconomic characteristics, for instance if they differed substantially across some of the groups analyzed. Nevertheless, these results present a sufficiently solid tentative case about the nature and usefulness of the classical cut-offs for psychological well-being, although they will need to be confirmed with complementary analyses that can control for additional variables. Furthermore, this is a cross-sectional study, which does not allow inferences about cause and effect. Despite the fact that obesity may impair quality of life, poor HRQOL could be due to other factors and in turn contribute to weight gain and obesity.

Understanding the relation between weight status and psychological well-being is important for informing decisions in clinical practice, such as achieving a better tailoring between weight control treatments and participants, and generally for a better recognition of the quality of the subjective experience (of being overweight and obese) in a large and increasing segment of the population. While the physical outcomes of obesity are relatively well-known, psychological correlates are much less well-understood [52]. The results of this research show that psychological well-being differs with weight status and that addressing well-being in weight control programs might be especially important given that individuals seeking treatment have lower well-being scores than individuals with an equally high weight but not seeking outside help. Unfortunately, relatively few studies have addressed psychological changes during conservative or lifestyle weight control programs [53]. Some treatment studies have shown that losing weight and participating in behavioral group weight control programs including a component addressing well-being is associated with decreases in body dissatisfaction and increased self-esteem [54, 55], suggesting that including strategies to improve psychological well-being pays off; for example, establishing more realistic goals and expectations for participants' weight and body shape, confronting ideal physiques with the real limits in biological capacities, helping participants understand the concept of body image (i.e., a subjective construct independent of physical appearance), providing choice to participants physical activities, increasing physical activity knowledge and self-efficacy, and depreciating eating rigid restraint and valuing more flexible forms of restraint.

In conclusion, BMI categories appear useful in identifying increased psychological risk in women with a BMI below $40 \mathrm{~kg} / \mathrm{m}^{2}$. Across most psychosocial outcomes, significantly higher impairment in quality of life and well-being were observed at a BMI above $25 \mathrm{~kg} / \mathrm{m}^{2}$. HRQOL measures may provide a better understanding of psychological factors that impact on an individual's efforts to control his or her weight in the long term. Thus, health care providers working in this area should be aware of these findings and include measures of quality of life and psychological well-being in treatment assessment batteries, and design programs that address HRQOL and well-being independently of weight loss. 
Vieira et al: Usefulness of Standard BMI Cut-Offs for Quality of Life and

Psychological Well-Being in Women

\section{Acknowledgements}

This study was funded by grants by the Portuguese Science and Technology Foundation (FCT-POCI/ DES/57705/2004 and SFRH/BD/31408/2006 to Paulo N. Vieira) and the Calouste Gulbenkian Foundation (grant number 65565/2004). The investigators are also grateful to the Oeiras City Council, Nestlé Portugal, and IBESA for their additional financial support.

\section{Disclosure Statement}

The authors declare no conflict of interest.

\section{References}

1 Fontaine KR, Redden DT, Wang C, Westfall AO, Allison DB: Years of life lost due to obesity. JAMA 2003;289: 187-193.

2 WHO: Obesity: Preventing and Managing the Global Epidemic. Geneva, World Health Organization, 1998.

- 3 Kopelman PG: Obesity as medical problem. Nature 2000;404:635-643.

- 4 Klein S, Burke LE, Bray GA, Blair S, Allison DB, Pi-Sunyer X, et al: Clinical implications of obesity with specific focus on cardiovascular disease: a statement for professionals from the American Heart Association Council on Nutrition, Physical Activity, and Metabolism: endorsed by the American College of Cardiology Foundation. Circulation 2004;110:2952-2967.

- 5 Wyatt SB, Winters KP, Dubbert PM: Overweight and obesity: prevalence, consequences, and causes of a growing public health problem. Am J Med Sci 2006;331:166-174.

- 6 Sullivan PW, Ghushchyan V, Wyatt HR, Wu EQ, Hill JO: Impact of cardiometabolic risk factor clusters on health-related quality of life in the U.S. Obesity (Silver Spring) 2007;15:511-521.

- 7 Doll HA, Petersen SE, Stewart-Brown SL: Obesity and physical and emotional well-being: associations between body mass index, chronic illness, and the physical and mental components of the SF-36 questionnaire. Obes Res 2000;8:160-170.

- 8 Hopman WM, Berger C, Joseph L, Barr SI, Gao Y, Prior JC, et al: The association between body mass index and health-related quality of life: data from CaMos, a stratified population study. Qual Life Res 2007;16:1595-1603.

9 Kolotkin RL, Meter K, Williams GR: Quality of life and obesity. Obes Rev 2001; 2:219-229.

10 Fontaine KR, Barofsky I: Obesity and health-related quality of life. Obes Rev 2001;2:173-182.

11 Schwartz MB, Brownell KD: Obesity and body image. Body Image 2004;1:43-56.

12 NHLBI: Clinical Guidelines on the Identification, Evaluation, and Treatment of Overweight and Obesity in Adults: The Evidence Report. Washington, DC, NIH - National Heart, Lung, and Blood Institute, 1998.

13 Gregg EW, Cheng YJ, Cadwell BL, Imperatore G, Williams DE, Flegal KM, et al: Secular trends in cardiovascular disease risk factors according to body mass index in US adults. JAMA 2005;293:1868-1874.

-14 Flegal KM, Graubard BI, Williamson DF, Gail MH: Excess deaths associated with underweight, overweight, and obesity. JAMA 2005;293:1861-1867.

15 NIH: National Institutes of Health: The Practical Guide: Identification, Evaluation, and Treatment of Overweight and Obesity in Adults. Washington, DC, National Institutes of Health, 2000.

16 do Carmo I, Dos Santos O, Camolas J, Vieira J, Carreira M, Medina L, et al: Overweight and obesity in Portugal: national prevalence in 2003-2005. Obes Rev 2008;9:11-19.

17 Faith MS, Matz PE, Jorge MA: Obesity-depression associations in the population. J Psychosom Res 2002;53: 935-942.

18 Faith MS, Calamaro CJ, Dolan MS, Pietobelli A: Mood disorders and obesity. Curr Opin Psychiatry 2004;17:9-13.

-19 McElroy SL, Kotwal R, Malhotra S, Nelson EB, Keck PE, Nemeroff CB: Are mood disorders and obesity related? A review for the mental health professional. J Clin Psychiatry 2004;65:634-651, quiz 730.

20 Teixeira PJ, Going SB, Sardinha LB, Lohman TG: A review of psychosocial pre-treatment predictors of weight control. Obes Rev 2005,6:43-65.

-21 Kolotkin RL, Crosby RD, Williams GR: Health-related quality of life varies among obese subgroups. Obes Res 2002;10:748-756.

22 Fontaine KR, Bartlett SJ, Barofsky I: Health-related quality of life among obese persons seeking and not currently seeking treatment. Int J Eat Disord 2000;27:101-105.

23 Cooper Z, Fairburn CG, Hawker DM: Cognitive-Behavioral Treatment of Obesity: A Clinician's Guide. New York, Guilford, 2003.

24 Sarwer DB, Wadden TA, Foster GD: Assessment of body image dissatisfaction in obese women: specificity, severity, and clinical significance. J Consult Clin Psychol 1998;66:651-654.

25 Teixeira PJ, Palmeira AL, Branco TL, Martins SS, Minderico CS, Barata JT, et al: Who will lose weight? A reexamination of predictors of weight loss in women. Int J Behav Nutr Phys Act 2004;1:12. 
Vieira et al.: Usefulness of Standard BMI Cut-Offs for Quality of Life and

Psychological Well-Being in Women

26 Silva MN, Markland D, Minderico CS, Vieira PN, Castro MM, Coutinho SR, et al: A randomized controlled trial to evaluate self-determination theory for exercise adherence and weight control: rationale and intervention description. BMC Public Health 2008;8:234.

27 Silva MN, Santos TC, Coutinho SR, Marcelino MS, Vieira PN, Tomás RA, et al: O Programa 'PESO COMUNITÁRIO' ['PESO COMUNITÁRIO’ Program]. Revista de Informação e Divulgação Científica sobre Doenças do Comportamento Alimentar 2009;6:1-12.

28 Ware JE Jr, Kosinski M: SF-36 Physical and Mental Health Summary Scales: A Manual for Users of Version 1, ed 2. Lincoln, Qualitymetric, 2001.

29 Ware JE Jr, Kosinski M, Keller SD: SF- $12{ }^{\circledR}$ : How to Score the SF-12 ${ }^{\circledR}$ Physical and Mental Health Summary Scalesed 3. Lincoln, Qualitymetric, 1998.

30 Ware JE Jr, Kosinski M, Keller SD: A 12-item short-form health survey: construction of scales and preliminary tests of reliability and validity. Med Care 1996;34:220-233.

-31 Wee CC, Davis RB, Hamel MB: Comparing the SF-12 and SF-36 health status questionnaires in patients with and without obesity. Health Qual Life Outcomes 2008;6:11.

-32 Kolotkin RL, Crosby RD, Kosloski KD, Williams GR: Development of a brief measure to assess quality of life in obesity. Obes Res 2001; 9:102-111.

-33 Engel SG, Kolotkin RL, Teixeira PJ, Sardinha LB, Vieira PN, Palmeira AL, et al: Psychometric and crossnational evaluation of a Portuguese version of the Impact of Weight on Quality of Life-Lite (IWQOL-Lite) questionnaire. Eur Eat Disord Rev 2005;13:133-143.

34 Rosenberg M: Society and the Adolescent Self-Image. Princeton, Princeton University Press, 1965.

-35 Williamson DA, Davis CJ, Bennett SM, Goreczny AJ, Gleaves DH: Development of a simple procedure for assessing body image disturbances. Behav Asses 1989;15:57-68.

-36 Cooper PJ, Taylor MJ, Cooper Z, Fairburn CG: The development and validation of a body shape questionnaire. Int J Eat Disord 1987;6:485-494.

-37 Cash TF, Melnyk SE, Hrabosky JI: The assessment of body image investment: an extensive revision of the appearance schemas inventory. Int J Eat Disord 2004;35:305-316.

38 Lohman T, Roche A, Martorell R: Anthropometric Standardization Manual. Champaign, Human Kinetics, 1988.

39 Santos 0, do Carmo I, Camolas J, Vieira J: Validity of self reported weight and height in the evaluation of body mass index in the Portuguese population (in Portuguese). ENDO, Endocrinologia, Metabolismo \& Nutrição 2009;3:157-168.

$\checkmark 40$ Coakley EH, Kawachi I, Manson JE, Speizer FE, Willet WC, Colditz GA: Lower levels of physical functioning are associated with higher body weight among middle-aged and older women. Int J Obes Relat Metab Disord 1998;22:958-965.

41 Lean ME, Han TS, Seidell JC: Impairment of health and quality of life in people with large waist circumference. Lancet 1998;351:853-856.

42 Ford ES, Moriarty DG, Zack MM, Mokdad AH, Chapman DP: Self-reported body mass index and healthrelated quality of life: findings from the Behavioral Risk Factor Surveillance System. Obes Res 2001;9: 21-31.

43 Larsson U, Karlsson J, Sullivan M: Impact of overweight and obesity on health-related quality of life - a Swedish population study. Int J Obes Relat Metab Disord 2002;26:417-424.

-44 Ackermann RT, Edelstein SL, Narayan KM, Zhang P, Engelgau MM, Herman WH, Marrero DG; Diabetes Prevention Program Research Group: Changes in health state utilities with changes in body mass in the Diabetes Prevention Program. Obesity (Silver Spring) 2009;17:2176-2181.

45 Jia H, Lubetkin EI: The impact of obesity on health-related quality-of-life in the general adult US population. J Public Health (Oxf) 2005:27:156-164.

46 Han TS, Tijhuis MA, Lean ME, Seidell JC: Quality of life in relation to overweight and body fat distribution. Am J Public Health 1998;88:1814-1820.

47 Puhl RM, Heuer CA: The stigma of obesity: a review and update. Obesity (Silver Spring) 2009;17:941-964.

48 Puhl RM, Brownell KD: Psychosocial origins of obesity stigma: toward changing a powerful and pervasive bias. Obes Rev 2003;4:213-227.

49 Fitzgibbon ML, Stolley MR, Kirschenbaum DS: Obese people who seek treatment have different characteristics than those who do not seek treatment. Health Psychol 1993;12:342-345.

50 Kolotkin RL, Norquist JM, Crosby RD, Suryawanshi S, Teixeira PJ, Heymsfield SB, et al: One-year healthrelated quality of life outcomes in weight loss trial participants: comparison of three measures. Health Qual Life Outcomes 2009; 7:53.

51 Hays RD, ed. Generic versus disease-targeted instruments; in Fayers PM, Hays RD (eds): Assessing Quality of Life in Clinical Trials: Methods and Practice. . New York, Oxford University Press, 2005.

52 Friedman MA, Brownell KD: Psychological correlates of obesity: moving to the next research generation. Psychol Bull 1995;117:3-20.

53 Vieira P, Mata J, Silva MN, Coutinho S, Santos T, Minderico C, et al: Predictors of psychological well-being during behavioral obesity treatment in women. J Obes. 2011;2011:936153.

54 Palmeira AL, Teixeira PJ, Branco TL, Martins SS, Minderico CS, Barata JT, et al: Predicting short-term weight loss using four leading health behavior change theories. Int J Behav Nutr Phys Act 2007;4:14.

55 Teixeira PJ, Silva MN, Coutinho SR, Palmeira AL, Mata J, Vieira PN, et al: Mediators of weight loss and weight loss maintenance in middle-aged women. Obesity (Silver Spring) 2010;18:725-735. 